\title{
Cognitive Impairment in Late-Life Depression: A Comparative Study of Healthy Older People, Late-Life Depression, and Mild Alzheimer's Disease Using Multivariate Base Rates of Low Scores
}

\section{OPEN ACCESS}

Edited by:

Marie-Christine Gely-Nargeot,

Université Paul Valéry, France

Reviewed by:

Marina Avila Villanueva,

Fundacion Centro De Investigacion De Enfermedades Neurologicas, Spain

Ernest Marek Tyburski,

University of Social Sciences and

Humanities, Poland

*Correspondence:

Gilles Chopard

gilles.chopard@gmail.com

Specialty section:

This article was submitted to

Psychology for Clinical Settings,

a section of the journal

Frontiers in Psychology

Received: 14 June 2021

Accepted: 24 August 2021

Published: 05 October 2021

Citation:

Masse C, Vandel P, Sylvestre G,

Noiret N, Bennabi D, Mauny $F$

Puyraveau M, Barsznica Y,

Dartevelle J, Meyer A, Binetruy M,

Lavaux M, Ryff I, Giustiniani J,

Magnin E, Galmiche J, Haffen E and

Chopard G (2021) Cognitive

Impairment in Late-Life Depression: A

Comparative Study of Healthy Older

People, Late-Life Depression, and

Mild Alzheimer's Disease Using

Multivariate Base Rates of Low

Scores. Front. Psychol. 12:724731.

doi: 10.3389/fpsyg.2021.724731
Caroline Masse ${ }^{1,2}$, Pierre Vandel ${ }^{1,2,3,4}$, Géraldine Sylvestre ${ }^{3,5}$, Nicolas Noiret $^{6}$, Djamila Bennabi ${ }^{1,2}$, Frédéric Mauny ${ }^{7,8}$, Marc Puyraveau ${ }^{7}$, Yoan Barsznica ${ }^{1,2,5}$, Jonathan Dartevelle ${ }^{3}$, Agatha Meyer ${ }^{3}$, Mickaël Binetruy ${ }^{3}$, Marie Lavaux ${ }^{3}$, Ilham Ryff ${ }^{1,5}$, Julie Giustiniani ${ }^{1,2}$, Eloi Magnin ${ }^{2,5}$, Jean Galmiche ${ }^{3}$, Emmanuel Haffen ${ }^{1,2,4}$ and Gilles Chopard ${ }^{1,2,3,5 *}$

${ }^{1}$ Department of Clinical Psychiatry, Besançon University Hospital, Besançon, France, ${ }^{2}$ Laboratory of Neurosciences and Cognitive Psychology, University of Bourgogne Franche-Comté, Besançon, France, ${ }^{3}$ Association for the Development of Applied Neuropsychology, Besançon, France, ${ }^{4}$ Clinical Investigation Center 1431-INSERM, Besançon University Hospital, Besançon, France, ${ }^{5}$ Department of Neurology, Memory Resource and Research Center (CM2R), Besançon University Hospital, Besançon, France, ${ }^{6}$ Research Centre on Cognition and Learning (CeRCA), UMR 7295 CNRS, University of Poitiers and University of Tours, Poitiers, France, ${ }^{7}$ Methodology Unit, UMETh, Clinical Investigation Center 1431-INSERM, Besançon, France, ${ }^{8}$ Laboratory of Chrono-Environnement, UMR 6249 CNRS, University of Bourgogne Franche-Comté, Besançon, France

Late-Life Depression (LLD) is often associated with cognitive impairment. However, distinction between cognitive impairment due to LLD and those due to normal aging or mild Alzheimer's Disease (AD) remain difficult. The aim of this study was to present and compare the multivariate base rates of low scores in LLD, mild AD, and healthy control groups on a battery of neuropsychological tests. Participants (ages 60-89) were 352 older healthy adults, 390 patients with LLD, and 234 patients with mild AD (i.e., MMSE $\geq 20$ ). Multivariate base rates of low scores (i.e., $\leq 5$ th percentile) were calculated for each participant group within different cognitive domains (verbal episodic memory, executive skills, mental processing speed, constructional praxis, and language/semantic memory). Obtaining at least one low score was relatively common in healthy older people controls (from 9.4 to 17.6\%), and may thus result in a large number of false positives. By contrast, having at least two low scores was unusual (from 0.3 to $4.6 \%$ ) and seems to be a more reliable criterion for identifying cognitive impairment in LLD. Having at least three low memory scores was poorly associated with LLD (5.9\%) compared to mild AD $(76.1 \%)$ and may provide a useful way to differentiate between these two conditions $\left[\chi_{(1)}^{2}\right.$ $=329.8, p<0.001$; Odds Ratio $=50.7,95 \% \mathrm{Cl}=38.2-77.5]$. The multivariate base rate information about low scores in healthy older people and mild AD may help clinicians to identify cognitive impairments in LLD patients, improve the clinical decision-making, and target those who require regular cognitive and clinical follow-up.

Keywords: late-life depression, Alzheimer's disease, older people, base rates, low scores, false positive, misdiagnosis, cognitive impairment 


\section{INTRODUCTION}

Late-life depression (LLD), defined as a major depressive episode occurring in individuals 60 years or older (Bhalla and Butters, 2011; Koening et al., 2014), independent of age at onset (O'Hara et al., 2006), is a heterogeneous mood disorder that has been found to have negative impact effect on people's health-related quality of life (Kiosses et al., 2001). In a clinical setting, patients with LLD frequently report subjective cognitive complaints (Gonda et al., 2004) and may show cognitive impairment in several neuropsychological domains including, most notably, executive function (Lockwood et al., 2002; Dybedal et al., 2013), psychomotor speed (Butters et al., 2004; Bennabi et al., 2013), and episodic memory (Herrmann et al., 2007; Dybedal et al., 2013). Visuospatial ability (Butters et al., 2004), semantic memory, and oral language (O'Hara et al., 2006) have also been found to be impaired in patients with LLD.

However, the pattern of cognitive impairment in LLD remains unclear and varies across studies due to methodological factors such as differences in patients sampled or the variety of tools used to measure cognition (Jaeger et al., 2006; Godin et al., 2007). In addition, most studies available had modest sample sizes (Dybedal et al., 2013; Roca et al., 2015) or reported cognitive functioning in terms of group means in a casecontrol design (Herrmann et al., 2007; Korsnes and Ulstein, 2014) that may obscure the degree of cognitive impairment in LLD (Gualtieri and Morgan, 2008; Iverson et al., 2011). An alternative approach for interpretation pattern of cognitive impairment is to determine the prevalence of low test-scores within a neuropsychological battery (Gualtieri and Morgan, 2008; Iverson et al., 2008, 2011; Brooks et al., 2011; Holdnack et al., 2017).

However, identification of cognitive impairment in patients with LLD remains difficult without taking into account normal cognitive variability in the healthy older population. Indeed, a great deal of research has demonstrated that the presence of one or more low scores was common among healthy older adults when multiple measures were considered simultaneously rather than in isolation (Palmer et al., 1998; Brooks et al., 2012; Gunner et al., 2012). For example, when considering performance across all subtests from the CERAD (Consortium to Establish a Registry for Alzheimer's Disease) neuropsychological assessment battery, $60.6 \%$ of the healthy older participants (aged 49-92 years) obtained one or more score at or below the $10^{\text {th }}$ percentile (Mistridis et al., 2015). Using the RAPID (Regional Network for Diagnostic Aid and Management of Patients with Cognitive Impairment) neuropsychological battery,

\footnotetext{
Abbreviations: AD, Alzheimer's disease; BEC 96, battery of cognitive efficacy; CERAD, consortium to establish a registry for Alzheimer's disease; COT, crossingoff test; DO30, denomination of 30 images; FCSRT, free and cued selective reminding test; GRECO, group of research and cognitive assessments; IST, Isaacs set test; LLD, late-life depression; MIS, memory impairment screen; MMSE, minimental state examination; NINCDS-ADRDA, National Institute of Neurological and Communicative Disorders and Stroke Alzheimer's Disease and Related Disorders Association for probable AD; RAPID, regional network for diagnostic aid and management of patients with cognitive impairment; TMTA, trail making test, part A; TMTB, trail making test, part B.
}

we previously found that $40.1 \%$ of the normative sample (individuals aged 50-89 years) obtained one or more test scores at or below the 5th percentile (Sylvestre et al., 2017). These findings suggest that isolated low scores may be erroneously considered impaired performances and lead to a false positive interpretation (Schretlen et al., 2008).

Many other studies (Palmer et al., 1998; Schretlen et al., 2008; Brooks et al., 2009a; Gunner et al., 2012; Oltra-Cucarella et al., 2019) also highlighted the need to consider base rates of low scores in healthy older individuals (i.e., false positive) in drawing inferences from low-test performances in patients, including those with neurological or psychiatric disorders (Brooks et al., 2009b; Karr et al., 2017). Indeed, the presence of cognitive impairment in patients with LLD may be sometimes due to the development of incipient dementia such Alzheimer's disease (AD) (Rushing et al., 2014, Ly et al., 2021). In clinical practice, the distinction of cognitive impairment related to LLD from those associated with early stage of $\mathrm{AD}$ is particularly difficult (Swainson et al., 2001; Foldi et al., 2003; Mazur-Mosiewicz et al., 2011; Gasser et al., 2018; Lanza et al., 2020a) and may lead to misdiagnosis in the older population (Rotomskis et al., 2015).

In view of the above mentioned, the aim of the present study was to describe the cognitive performance in patients with LLD in comparison with those with mild $\mathrm{AD}$ and a healthy control group. To achieve this aim, this study examines and presents the multivariate base rates of low scores on the RAPID battery in patients with LLD, mild $\mathrm{AD}$, and older healthy adults. It is hypothesized that patients would have more low scores on the RAPID test battery compared with healthy older people controls. It is further hypothesized that the base rate information could help to distinguish cognitive impairments associated with LLD from those observed with mild $\mathrm{AD}$ or normal aging.

\section{METHODS \\ Participants}

The study sample consisted of a healthy older people control group and two clinical groups including patients with LLD and patients with $\mathrm{AD}$.

The healthy older people control group were subjects drawn from the RAPID normative sample whose neuropsychological data had been initially collected previously (Ferreira et al., 2010). The design and methods for the RAPID normative data have been described in detail elsewhere (Ferreira et al., 2010). Briefly, to be included in the study, subjects had to speak and comprehend French, have no visual deficits or hearing loss that could interfere with the administration of neuropsychological testing, and had to live independently according to the "instrumental activities of daily living" (Lawton and Brody, 1969). Any participant with a previous medical history of a neurological disease (i.e., head trauma, stroke, dementia, Parkinson's disease, epilepsy, or brain tumor) or a psychiatric disorder (i.e., major depression, schizophrenia, bipolar disorder) was not included. As older adults represent the population of interest, individuals under 60 years of age were not included, thus the final group consisted of 352 healthy older people controls aged $60-89$ years. 
The clinical groups were convenience samples of patients with LLD or with AD. All patients had been referred to one of the nine inpatient or outpatient local memory consultations centers in the Franche-Comté Region (France) between 2008 and 2016. Cognitive data on all patients were retrospectively obtained from the database Rapid-Fr network (Bereau et al., 2015). The aim of this health network, financed by the French government, is to coordinate memory consultations in the geographical area of Franche-Comté (France). All patients were between 60 and 89 years old. Exclusion criteria were determined by reviewing the medical records.

Patients with LLD met the diagnostic criteria of major depression disorder according to the Diagnostic and Statistical Manual of Mental Disorders, Fourth Edition (DMS-IV) (American Psychiatric Association, 1994) and after a comprehensive clinical interview by a psychiatrist. All patients were or had been recently hospitalized and all were on medication. Exclusion criteria were: psychotic features, schizophrenia, bipolar disorder, current, or past history of neurological disease (e.g. dementia, head trauma, Parkinson's disease, epilepsy) substance abuse or a history of electroconvulsive treatment within the past 12 weeks. The final LLD sample included 390 patients.

The AD patients met National Institute of Neurological and Communicative Disorders and Stroke Alzheimer's Disease and Related Disorders Association for probable AD (NINCDSADRDA criteria) (McKhann et al., 1984) after full workup including neurologic, cognitive, imaging, and laboratory tests. Exclusion criteria were: concurrent neurological disorder, an acute stroke and a Fazekas score $>2$ to avoid mixtures of vascular and neurodegenerative processes (Fazekas et al., 1993). Given that depressive symptoms are commonly reported in patients with AD (20-30\%) (Lyketsos et al., 2002; Zubenko et al., 2003) we did not exclude them from this study (Foldi et al., 2003). Because the differentiation between of depression from $\mathrm{AD}$ in older age is more difficult in the earliest stages of AD (Rotomskis et al., 2015), only mild $\mathrm{AD}$ patients (i.e., MMSE $\geq 20$ ) were included in the current study. The final AD sample included 234 patients.

\section{Neuropsychological Assessment}

The RAPID battery was developed by a clinical research consortium in the Franche-Comte region (France) using the same standardized evaluation. The purpose of this consortium was to facilitate patient care management throughout the Franche-Comté region using a common neuropsychological battery of tests and software database (Bereau et al., 2015). All the tests of this battery were initially normed based on the same normative sample for a broad range of ages and educational levels (Ferreira et al., 2010).

All participants were administered the RAPID battery by trained neuropsychologists. The full test battery takes approximately $60 \mathrm{~min}$ to complete and includes nine tests that yield 13 primary independent scores measuring five cognitive domains: verbal episodic memory, executive skills, mental processing speed, constructional praxis, and language/semantic memory. The tests administered for each domain are described below.

\section{Assessment of Verbal Episodic Memory}

The Free and Cued Selective Reminding Test (FCSRT, Grober and Buschke, 1987). We used a french adaptation by Van der Linden et al. (2004). This test assesses the ability to learn a 16 written word list that refers to 16 semantic categories. After an encoding phase, participants have to perform three successive recall trials separated by an interfering task. Each trial includes two parts. First, each participant had to freely recall as many items as possible. Next, an orally presented semantic category (e.g., what was the name of the fish?) was provided for the words that were not spontaneously retrieved by the participants. The total free recall score (from 0 to 48 ) (i.e., participants are asked to retrieve the words spontaneously) and the total cued recall score (i.e., participants are asked to retrieve the words with the help of a semantic cue) were considered.

The Memory Impairment Screen (MIS, Buschke et al., 1999): a French version of the MIS was used (Chopard et al., 2007). The MIS is a 4-min, four-item delayed free- and cued-recall memory test. After an interfering task lasting at least $2 \mathrm{~min}$, the subjects are invited to reproduce the words learned in any order over $20 \mathrm{~s}$ (free recall). A cued recall is proposed for any words not mentioned using free recall. For each word, the score for a correct answer is two points for free recall and one point for cued recall. The total MIS score ranged from 0 to 8 was considered.

The word delayed recall of the Mini-Mental State Examination (MMSE) (Folstein et al., 1975): the MMSE is a global cognitive efficiency evaluation through use of 30 items to assess orientation, calculation, memory, language, and visio-constructional abilities. In this study, a consensual French version developed by GRECO (Group of Research and Cognitive Assessments) was used (Kalafat et al., 2003). The delayed recall of the three words (from 0 to 3 ) was considered.

\section{Assessment of Executive Functions}

The Trail Making Test, part B (TMTB, Reitan, 1958): participants are required to connect numbers and letters alternatively as quickly as possible. The total time to complete the TMT part $\mathrm{B}$ was considered as well as the total number of errors (i.e., sequential errors and/or perseverative errors).

The Isaacs Set Test (IST, Isaacs and Kennie, 1973): the IST is a 1-min verbal category fluency task. The subject has to orally produce as many words as possible in $15 \mathrm{~s}$ for each of the following categories: colors, animals, fruit, and cities. The total number of items named was considered (any repeated words or intrusions are not included).

\section{Assessment of Processing Speed}

The Trail Making Test part A (TMTA, Reitan, 1958): participants are required to connect with lines 25 circles numbered from 1 to 25 as quickly as possible. The total time to complete the TMTA was considered.

The Crossing-Off Test (COT, Botwinick and Storandt, 1973): the COT is a psychomotor task in which the participants have to make a slash mark through a set of 96 horizontal lines, as quickly as possible. There are eight lines per row, and individuals cross out the lines from left to right, one row after another. This test 
is scored as the number of lines (96) crossed out per second $(t)$ times 100 (Index of rapidity $=96 / t \times 100$ ).

\section{Assessment of Constructional Praxis}

Copy of triangles from the Battery of Cognitive Efficacy (BEC 96): the copy of the triangles of the cognitive assessment battery test in 96 items (Signoret et al., 1998) is a test in which the subject must copy a geometric figure according to a model that is presented. This figure is made up of a set of three intersecting triangles. The total final score, which varies from 0 to 6 , was considered.

The pentagon copy of MMSE (Folstein et al., 1975): copying the overlapping pentagons is a standard sub-item of the MMSE. It was scored dichotomously as either correct (1) or incorrect (0).

\section{Assessment of Language/Semantic Memory}

Oral name of images: oral denomination of 30 images (D030, Ferreira et al., 2010) is a test in which the subject must name 10 animals, 10 objects, and 10 actions. These images are from the BEC 96 (Signoret et al., 1998), the test D080 (Metz-Lutz et al., 1991), and the Montreal-Toulouse test of aphasia review protocol (Nespoulous et al., 1992). The overall score, made up of the total number of correct answers (from 0 to 30), was retained.

Categorical Matching: the Categorical Matching Test (Ferreira et al., 2010) assesses the subject's ability to perform semantic associations in the presence of distractors. The subject must designate one of three visual items, the one that is semantically connected to the target item. The total score of correct answers, which ranges from 0 to 10 , was considered.

It should be noted that in our study sample the diagnosis of $\mathrm{AD}$ was not entirely blind to cognitive performance and therefore raises the question of a partial circularity. However, the construct of base rates of low scores was only conceived after the RAPID data were collected. Moreover, other tests such as the California Verbal Learning Test (Delis et al., 1987), the Wechsler Memory Scale (Wechsler, 2001, 2012), the Delayed Matchingto-sample Task (Barbeau et al., 2004; Rullier et al., 2014), the copy, immediate recall, and delayed recall conditions of the ReyOsterrieth Complex Figure (Osterrieth, 1944; Rey, 1959; Meyers and Meyers, 1994), the Stroop test (Stroop, 1935), the GRECO neuropsychological semantic battery (Merck et al., 2011), the phonemic and semantic verbal fluency tests (Cardebat et al., 1995), or the oral denomination of 80 images (Metz-Lutz et al., 1991) in addition to the neuropsychological RAPID test Battery, have also been used to further assess the cognitive functioning contributing to limit the risk of circularity.

\section{DATA ANALYSIS}

Given that most of the primary measures of the RAPID test battery did not meet the normal distribution criteria (Ferreira et al., 2010), a low score was defined as less than or equal to the 5 th percentile, which is a common psychometric criterion used in clinical practice to determine "cognitive impairment" (Lezak et al., 2004). This cut-off score was also included in previous multivariate base rate analyses (Brooks et al., 2009a,b; Iverson
TABLE 1 | Demographic characteristics of the samples.

\begin{tabular}{lccc}
\hline & HC & LLD & Mild AD \\
\hline Sample size & 352 & 390 & 234 \\
Mean age (SD) & $72.9(7.7)$ & $73.1(7.7)$ & $78.9(6.1)$ \\
Age range & $60-89$ & $60-89$ & $60-89$ \\
Education level & & & \\
$\quad$ High (\%) & 16.1 & 13.4 & 23.5 \\
$\quad$ Middle (\%) & 32.5 & 32 & 28.2 \\
$\quad$ Low (\%) & 51.4 & 54.6 & 48.3 \\
Male/Female (\%) & $37 / 63$ & $29 / 71$ & $36 / 64$ \\
\hline
\end{tabular}

$H C$, healthy controls; LLD, late life depression; $A D$, Alzheimer's disease; $S D$, standard deviation. High (i.e., $>11$ years of education), Middle (i.e., 8-11 years of education), Low ( $<8$ years of education).

et al., 2011; Ivins et al., 2015; Holdnack et al., 2017; Karr et al., 2017; Rivera et al., 2019).

The 5th percentile cut-off values for the 13 primary measures of the RAPID test battery were calculated in a previous study (Sylvestre et al., 2017) from the normative sample of older adults (Ferreira et al., 2010) based on three age categories (ranges 6069, 70-79, and 80-89 years) and three educational levels: high level (i.e., $>11$ years of education), middle level (i.e., 8-11 years of education), or the lowest educational level (i.e., $<8$ years of education).

As a reminder, to estimate the variability of the number of low scores in each of the RAPID primary measures, 1,000 bootstrap replicates were computed (Efron, 1992). Rather than limiting ourselves to an observed value for a small number of subjects, we wanted to add an uncertainty factor to our estimation. With the "bootstrapping" technique, we were able to calculate the variability of an estimation as the probability laws of this was unknown.

The multivariate base rates of low scores on the RAPID battery for the healthy older people controls, LLD, and AD group were determined by simultaneously examining the performance of 13 primary measures. For each subject, the total number of low scores (i.e., at or below the 5th percentile) was calculated across all primary measures. The multivariate base rates of low scores were further calculated as cumulative percentages for each of the three groups within different cognitive domains: verbal episodic memory, executive skills, mental processing speed, constructional praxis, and language/semantic memory. A Chisquare test was used to compare relevant group frequencies generated by cross tabulation.

\section{RESULTS}

The demographic characteristics for each of the three groups are shown in Table 1.

The base rates of low scores within specific cognitive domains are presented in Table 2. As seen in Table 2, it is common (between 9.4 and 17.6\%) for healthy older people to obtain at least one low score (i.e., $\geq 1$ ). For example, they were 17.6 and 
TABLE 2 | Base rates of low scores within specific cognitive domains of healthy controls and patients with late life depression and mild Alzheimer's Disease.

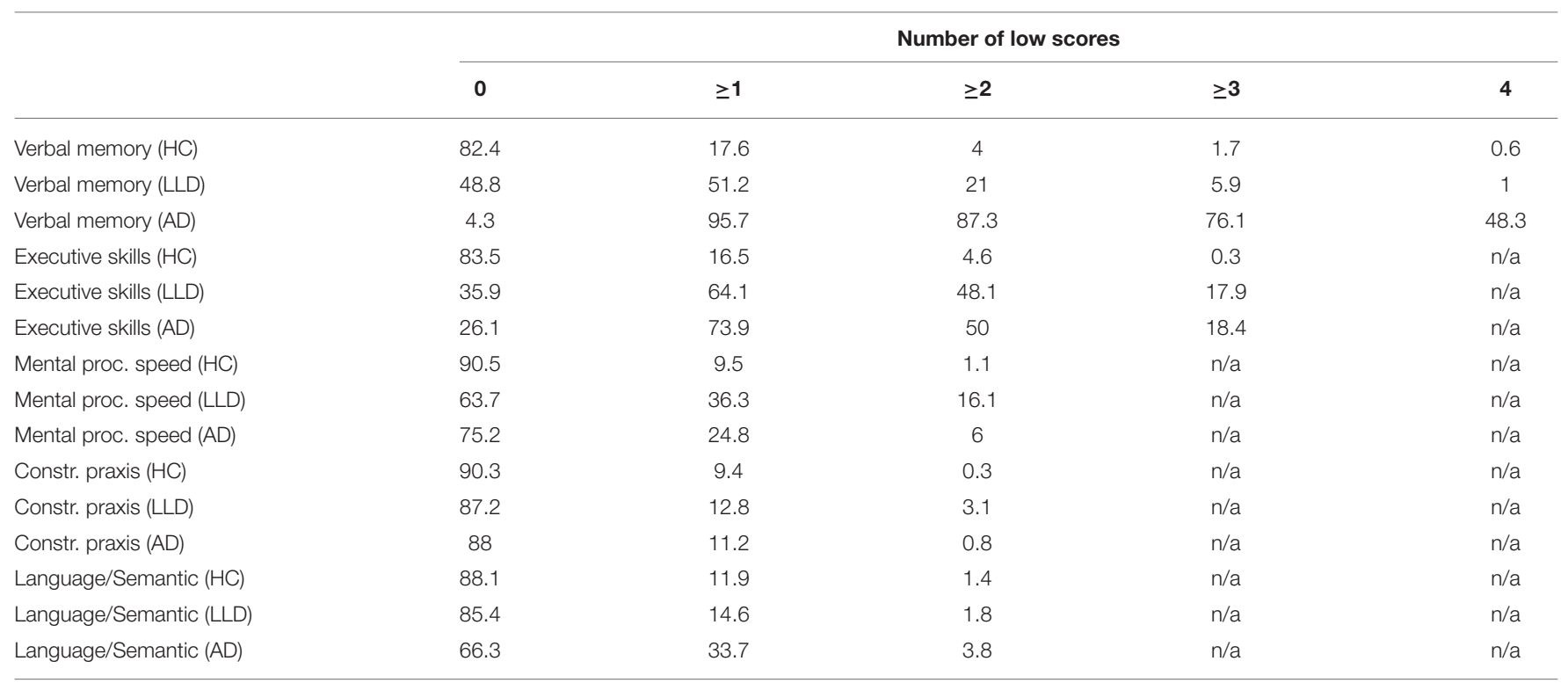

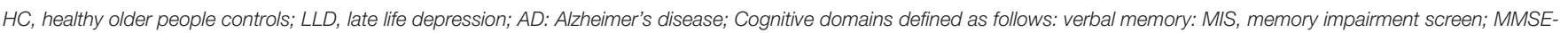

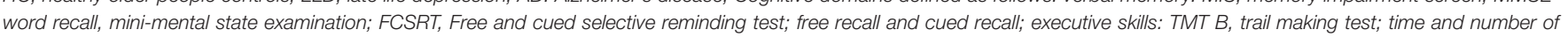

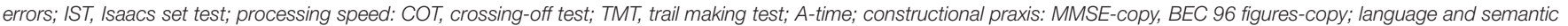
memory: categorical matching, naming test, n/a: not applicable.

$16.5 \%$ for verbal memory and executive function, respectively. The prevalence of having at least two low scores (i.e., $\geq 2$ ) dramatically decreased and varied from 0.3 to $4.6 \%$. For example, they were 4 and $4.6 \%$ for verbal memory and executive function, respectively. A great percentage of patients obtained at least one low score: between 12.8 and $64.1 \%$ for LLD, between 11.2 and 95.7\% for mild AD. The prevalence of having at least two low scores varied from 1.8 to $48.1 \%$ for LLD and from 0.8 to $87.3 \%$ for mild AD.

When comparing the cumulative percentages of participants in LLD and healthy older people control group, a larger percentage of patients with LLD had two or more low verbal memory scores than healthy controls ( 21 vs. $4 \%)\left[\chi_{(1)}^{2}=47.74, p\right.$ $<0.001$; Odds Ratio $=6.4,95 \% \mathrm{CI}=3.8-10.9]$. In the executive domain, a much higher percentage was found in patients with LLD $(48.1 \%)$ than in healthy older people controls $(4.6 \%)\left[\chi_{(1)}^{2}\right.$ $=175.38, p<0.001$; Odds Ratio $=19.4$, 95\% CI $=12.5-$ 30]. Patients with LLD are more likely to obtain two or more low processing speed scores $(16.1 \%)$ than healthy older people controls $(1.1 \%)\left[\chi_{(1)}^{2}=50.80, p<0.001\right.$; Odds Ratio $=16.8$, $95 \% \mathrm{CI}=7.7-36.4]$. For the constructional praxis, having two low scores occurred in $3.1 \%$ of the LLD patients and $0.3 \%$ of the healthy controls $\left[\chi_{(1)}^{2}=8.4, p<0.01\right.$; Odds Ratio $=11.1,95 \%$ $\mathrm{CI}=2.2-57]$. For the language/semantic memory domain the percentages look very similar (1.8 vs. $1.4 \%)$ in both groups $\left(\chi^{2}\right.$ $=0.16, p=0.68$; Odds Ratio $=1.3,95 \% \mathrm{CI}=0.4-4)$.

When comparing the cumulative percentages of participants in LLD and mild AD group (mean MMSE = 23.1 \pm 2.2 ), a larger percentage of patients with mild $\mathrm{AD}$ had two or more low verbal memory scores than LLD (87.3 vs. $21 \%)\left[\chi_{(1)}^{2}=257.81, p<\right.$ 0.001 ; Odds Ratio $=25.5,95 \% \mathrm{CI}=1.7-37.5]$. In the executive domain, the percentages look very similar in both groups (48.1 vs. $50 \%)\left[\chi_{(1)}^{2}=0.24, p=0.62\right.$; Odds Ratio $=1.1,95 \% \mathrm{CI}=$ $0.8-1.5]$. Patients with LLD are more likely to obtain two low processing speed scores than those with mild AD (16.1 vs. 6\%) $\left[\chi_{(1)}^{2}=13.44, p<0.001\right.$; Odds Ratio $\left.=3.0,95 \% \mathrm{CI}=1.7-5.3\right]$. For the constructional praxis $\left[\chi_{(1)}^{2}=3.29, p=0.07\right.$; Odds Ratio $=$ $0.27,95 \% \mathrm{CI}=0.06-1.2]$ and language/sematic memory domain $\left[\chi_{(1)}^{2}=2.46, p=0.11\right.$; Odds Ratio $\left.=2.19,95 \% \mathrm{CI}=0.8-5.8\right]$, there was no significant statistical difference.

Having three low scores in the executive domain, was found in the same proportion for both LLD (17.9\%) and $\mathrm{AD}$ (18.4\%) group $\left(\chi^{2}=0.02, p=0.89\right.$; Odds Ratio $\left.=1.03,95 \% \mathrm{CI}=0.7-1.5\right) . \mathrm{A}$ larger proportion of patients with mild $\mathrm{AD}(76.1 \%)$ than patients with LLD $(5.9 \%)$ had three or more low scores (i.e., $\geq 3$ ) in the verbal memory domain $\left[\chi_{(1)}^{2}=329.8, p<0.001\right.$; Odds Ratio $=$ 50.7, $95 \% \mathrm{CI}=38.2-77.5]$.

\section{DISCUSSION}

The results of the present study reiterate that a substantial proportion of healthy older individuals obtained one or more low scores on the RAPID battery even at a stringent cut-off value (i.e., at or below the 5 th percentile). They are consistent with previously reported studies on other neuropsychological test batteries (Heaton, 1991; Palmer et al., 1998; Brooks et al., 2009a, 2011; Karr et al., 2017) and confirmed that low scores are common in healthy older people when multiple test scores are simultaneously analyzed across a battery. This implies that isolated low scores obtained by an individual across multiple tests are not necessarily pathological or indicative of truly impaired 
functioning (Schretlen et al., 2008; Binder et al., 2009; Sylvestre et al., 2017). Thus, our data showed that from 9.4 to $17.6 \%$ of healthy older people obtained at least one low score on either measure in each cognitive domain. These findings suggest that an isolated low score may result in a large number of false positives and may have little relevance in clinical evaluation (Palmer et al., 1998; Lezak et al., 2004). Indeed, if one or more low scores at or below the 5 th percentile is used as a criterion for identifying memory, executive or speed processing impairment on the RAPID battery, it can be noted that, respectively, 17.6, 16.5 , and $9.5 \%$ of healthy controls obtained such a result (i.e., a potential false positive). It is also important to emphasize that these percentages are much higher than the theoretical base rate of $\leq 5 \%$ when interpreting a single score in isolation (Brooks et al., 2013; Karr et al., 2017; Rivera et al., 2019). By contrast, having two or more low scores could be used as a more confident criterion since this pattern of results was uncommon in healthy older people controls (from 0.3 to $4.6 \%$ ). This information on the base rate of low scores among healthy older adults is important since it may help clinicians to reduce the likelihood of misdiagnosing cognitive impairment among older depressed patients.

Indeed, many studies have already shown poor performance in verbal memory, executive function and processing speed in LLD (Baudic et al., 2004; Elderkin-Thompson et al., 2006; Dybedal et al., 2013). However, the majority of them reported results derived from comparisons of mean groups (i.e., average performance) in a case-control design, which may obscure the importance of cognitive impairment in patients with LLD (Gualtieri and Morgan, 2008; Iverson et al., 2011). It should be emphasized that a significant group difference does not inform about the proportion of patients who have cognitive impairment and those who have no cognitive impairment (Gualtieri and Morgan, 2008). This suggests that the average-to-average method is not sufficiently reliable to characterize the level of cognitive functioning in different samples of individuals (Ivins et al., 2015). From this perspective, presenting data in terms of frequency of low scores could be more informative and useful in clinical practice (Chelune, 2010; Iverson and Brooks, 2011; Ivins et al., 2015).

To the best of our knowledge, very few studies provided information about the prevalence of low scores for different cognitive domains in patients with LLD. One study (Dybedal et al., 2013) found that up to 50\% of patients with LLD aged 6085 years obtained a low score in at least one cognitive domain compared to $20 \%$ of the controls. Another study (Butters et al., 2004) showed that $61 \%$ of depressed patients aged 60 years and older had a low score in at least one domain compared to $32.5 \%$ of the controls. A recent research (Lanza et al., 2020b) found about one-third of depressed patients aged 54-81 years were below normal in executive function and about two out of three patients were below normal in memory function. However, in these researches, a low score was defined using the less stringent cut-off values (i.e., below the $10^{\text {th }}$ percentile or mean minus 1.5 standard deviation) of a very small control group $(n=18, n=$ 40 , and $n=40$, respectively) and not from large normative data stratified by age and education.
The comparison of the base rates of low scores in the LLD patients with that of mild $\mathrm{AD}$ showed a great overlap in the executive function. This result is in accordance with previous works and confirmed that tests of executive functions do not allow distinguish these two disorders (Swainson et al., 2001; Rushing et al., 2014). Executive dysfunction is common in LLD (Lockwood et al., 2002; Alexopoulos, 2003; Baudic et al., 2004; Herrmann et al., 2007; Dybedal et al., 2013) and may be broadly related to a slowed information processing speed (Butters et al., 2004) and frontostriatal circuit disorders caused by vascular lesions (Alexopoulos, 2006, Butters et al., 2008). In addition, executive dysfunction may also be secondary to a lack of motivation (Scheurich et al., 2008) or a decrease in effortful attention capacity (Elliot, 1998; Royall et al., 2012). The presence of executive impairment has also been demonstrated in the mild stages of $\mathrm{AD}$ in inhibition, task-switching, planning, flexibility, and concurrent manipulation of information (Colette et al., 1998; Perry et al., 2000; Stokholm et al., 2006; Godefroy et al., 2014).

This study also shows that a great percentage (51.2\%) of individuals with LLD obtained at least one low memory score (see Table 2). Episodic verbal memory has been found to be impaired in older people with depression (Butters et al., 2004; Sheline et al., 2006; Lamar et al., 2012). It has been argued that memory impairment in LLD may be related to executive dysfunction (Fossati et al., 2002; Herrmann et al., 2007; Lamar et al., 2012). In addition, depressed patients may show a lack of effortful attention that may contribute to reduced memory performance (Hasher and Zacks, 1979). This view is consistent with the fact that depressed patients have more difficulty with tasks that require effortful information processing than those requiring automatic information processing (Hasher and Zacks, 1979; Hammar, 2003; Hammar et al., 2003). Our results are consistent with this and showed that in our LLD patient sample, the frequency of having a low score on the free recall of the FCSRT (25\%) and of the MMSE (34\%) (high-demanding tasks) was higher than on the cued recall of the FCSRT (12\%) or the MIS (10\%) that require much fewer attention resources. This result may reflect difficulty in retrieving information during effortful memory tasks in LLD (Alexopoulos, 2001).

It is also worth noting that a great proportion $(76.1 \%)$ of individuals with mild $\mathrm{AD}$ obtained 3 or 4 low memory scores whereas this pattern of performance was uncommon $(5.9 \%)$ in LLD patients. This result may be explained by the fact that $\mathrm{AD}$ patients are impaired on all memory tasks including effortful or automatic process (Leyhe et al., 2017). Thus, it has been suggested that cued recall could allow to differentiate between poor memory due to depression and those related to $\mathrm{AD}$ since it was expected to minimize the decreased attention resources or lack of strategies found most often in the patients with depression (Ivaniou et al., 2005; Dierckx et al., 2007). However, in the present study, if only $12 \%$ of LLD had a low performance on the cued recall of the FCSRT, $66 \%$ of mild $\mathrm{AD}$ obtained such a pattern showing that this index of measure is moderately sensitive to minimal impairment at a mild stage of the disease. Conversely, a greater percentage of mild $\mathrm{AD}$ obtained a low free recall at the FCSRT ( $84 \%)$ but this measure lacks of specificity since $25 \%$ of LLD patients (i.e., false positive) obtained such a score, 
demonstrating a great overlap of this measure for differentiating these two conditions. Our findings thus suggest that using a pattern of low scores on multiple memory measures seems to be able to distinguish patients with LLD from patients with mild AD. They are not surprising and consistent with previous studies reported that memory tasks have relatively high power to discriminate $\mathrm{AD}$ and older depressed patients. However, these studies have focused on a single or overall cognitive composite score and were carried out in small samples size which could result in a probable lack of statistical power (Swainson et al., 2001; Foldi et al., 2003; Künig et al., 2006; Dierckx et al., 2007, 2011; Federico et al., 2008; Contador et al., 2010; Para et al., 2010; Croisile et al., 2011; Mazur-Mosiewicz et al., 2011; Rotomskis et al., 2015).

The present study has several limitations. First, as in some previous works (Gualtieri and Morgan, 2008; Iverson et al., 2011), our LLD group was a convenience sample: the intensity of depression, age of onset or number of prior episodes had not been recorded in the RAPID database. Nevertheless, the great majority of LLD patients were or had been hospitalized for major depression, and all were in regular contact with their psychiatrist, meaning that they had probably moderate or severe depression rather than a mild form of depression. Furthermore, it has been shown (Purcel, 1997) that inpatients performed worse on cognitive tests than the outpatients, and thereby may limit the generalizability of our study results. In the future, it would be interesting to collect this information in order to better characterize the pattern of cognitive impairment of this condition. Second, our study did not take into account pharmacological treatment that could affect cognitive performance in LLD patients. Indeed, all depressed patients were being treated with antidepressants at the time of neuropsychological testing, which could affect the cognitive performance of LLD patients. Non-tricyclic antidepressants are known to improve memory performance (Haynes et al., 2004; McIntyre et al., 2014), whereas those with anticholinergic properties have been found to impair memory performance (Thompson and Trimble, 1982). Third, no information were recorded in the RAPID database about vascular factors in patients with LLD. Many studies have revealed a strong association between LLD, cognitive impairment, cerebrovascular disease, and poor cognitive outcomes, including progressive dementia, especially AD (Butters et al., 2008). Further assessment of the impact on the possible role of vascular comorbidity in the prevalence of low cognitive scores in LLD will be needed. In addition, as for LLD patients, we also used a convenience sample of patients with $\mathrm{AD}$ that may not be representative of community-dwelling adults. Thus, the findings of this paper should be validated using a randomly recruited, nationally, representative samples. Lastly, the ecological validity of the RAPID battery has never been examined in communitydwelling older adults. However, it is worth noting that norms of the RAPID battery tests for older adults were obtained from the same sample, in testing conditions as close as possible as those of a patient referred to a neuropsychologist, i.e., with the same tests, in the same order and time of administration.
However, this study has the advantage of showing results from a large sample (742 participants), thereby making it possible to present the data in terms of frequency of low scores (Gualtieri and Morgan, 2008). Furthermore, the 5th percentile cut-off values used in this study to define a low score were determined from age-and education-adjusted normative data (Sylvestre et al., 2017) that help to minimize over-or underestimation of impairment due to these two potential confounding variables (Potter and Steffens, 2007).

Furthermore, it is also important to remember that the base rates of low scores are expected to increase both as the number of tests increases and with a more lenient cut-off (Schretlen et al., 2008; Binder et al., 2009; Iverson and Brooks, 2011). This means that higher rates of falsepositive low scores would have been reported in our healthy older people group if we had used a less stringent cut-off value (such as the 16th percentile) or a battery including a higher number of tests for each cognitive domain (OltraCucarella et al., 2019). This implies that a higher number of low test-scores should be used as a reliable criterion for identifying (Mistridis et al., 2015) or predicting (Bradfield et al., 2020) cognitive impairment. This emphasizes the need for clinicians to interpret isolated low scores with even greater caution when using a large number of tests with a less conservative cut-off.

The findings of the present study may have potential implications for clinical practice: for each cognitive domain, having at least one low score on the RAPID battery was common among our healthy older adult sample and cannot therefore be used to support the presence of cognitive impairment in patients with LLD (i.e., high risk of false positive). However, having at least two low scores seems to be a more valuable criterion for identifying cognitive impairment in LLD, given its low positive rates in healthy older people. The base rate of low scores could thus provide adjunctive information in the clinical assessment of patients with LLD. It could for instance help to target patients with LLD who exhibit more extensive executive dysfunction and maybe at higher risk of poor outcomes (Koening et al., 2014) since this is known to be associated with poor antidepressant response (Potter et al., 2004; Alexopoulos et al., 2005; Story et al., 2008) and lower remission rates (Potter et al., 2004; Sheline et al., 2006). More studies are needed to explain the relationship between executive dysfunction and poor antidepressant response in LLD (Pimontel et al., 2016). Moreover, it could be interesting to combine many factors (clinical, cognitive, imaging, genetic, and so on) in order to better determine the risk of non-remission to antidepressants (Masse-Sibille et al., 2018).

In the verbal memory domain, the presence of three or more low memory scores may help establish whether the memory impairment is secondary to geriatric depression or to neurodegenerative process such as $\mathrm{AD}$. This pattern of low scores could also be used as a red flag for memory impairment and should encourage the practitioner to target the LLD patient's follow-up. This point is relevant since LLD patients with poor memory performance have an increased risk of developing AD (Diniz et al., 2013; Kaup et al., 2016). It is an important 
challenge in psychiatry and neurology (Künig et al., 2006; Leyhe et al., 2017; Liguori et al., 2018) from a prognostic and therapeutic point of view (Birrer and Verumi, 2004; MazurMosiewicz et al., 2011; Rotomskis et al., 2015; Gasser et al., 2018). However, future longitudinal research should consider estimating whether the base rates analyzing low memory scores by using different cut-offs, could have a useful predictive value for people with LLD.

In conclusion, the present study highlights the importance of knowing the base rates of low scores across a battery of tests in healthy older adults and mild $\mathrm{AD}$ for detecting the presence of cognitive impairment in older adults with depression. This base rate information may help reduce the likelihood of misdiagnosing cognitive impairments, improve the clinical decision-making and target LLD patients who require careful and regular cognitive follow up.

\section{DATA AVAILABILITY STATEMENT}

The original contributions presented in the study are included in the article, further inquiries can be directed to the corresponding author.

\section{REFERENCES}

Alexopoulos, G. S. (2001). The depression-executive dysfunction syndrome of late life: a specific target for D3 agonists? Am. J. Geriatr. Psychiatry. 9, 2-28. doi: 10.1097/00019442-200102000-00004

Alexopoulos, G. S. (2003). Role of executive function in late-life depression. J. Clin. Psychiatry. 64, 18-23.

Alexopoulos, G. S. (2006). The vascular depression hypothesis: 10 years later. Biol. Psychiatry. 60, 1304-1305. doi: 10.1016/j.biopsych.2006.09.006

Alexopoulos, G. S., Kiosses, D. N., Heo, M., Murphy, C. F., Shanmugham, B., and Gunning-Dixon, F. (2005). Executive dysfunction and the course of geriatric depression. Biol. Psychiatry. 58, 204-210. doi: 10.1016/j.biopsych.2005.04.024

American Psychiatric Association (1994). Diagnostic and Statistical Manual of Mental Disorders. Fourth Edn. (DSM-IV). Washington, DC: American Psychiatric Association.

Barbeau, E., Didic, M., Tramoni, E., Joubert, S., Sontheimer, A., Ceccaldi, M., et al. (2004). Evaluation of visual recognition memory in MCI patients. Neurology 62, 1317-1322. doi: 10.1212/01.wnl.0000120548.24298.db

Baudic, S., Tzortzis, C., Barba, G. D., and Traykov, L. (2004). Executive deficits in elderly patients with major unipolar depression. J. Geriatr. Psychiatry Neurol. 4, 195-201. doi: 10.1177/0891988704269823

Bennabi, D., Vandel, P., Papaxanthis, C., Pozzo, T., and Haffen, E. (2013). Psychomotor retardation in depression: a systematic review of diagnostic, pathophysiologic, and therapeutic implications. Biomed. Rest. Int. 2013, 158746. doi: 10.1155/2013/158746

Bereau, M., Sylvestre, G., Mauny, F., Puyraveau, M., Baudier, F., Magnin, E., et al. (2015). Assessment of 10 years of memory consultations in the Franche-Comte: description and analysis of the RAPID regional database. Rev. Neurol. (Paris). 171, 655-661. doi: 10.1016/j.neurol.2015.04.008

Bhalla, R. K., and Butters, M. A. (2011). Cognitive functioning in late-life depression. BC Med. J. 53, 357-360.

Binder, L. M., Iverson, G. L., and Brooks, B. L. (2009). To err is human: "abnormal” neuropsychological scores and variability are common in healthy adults. Arch. Clin. Neuropsychol. 24, 31-46. doi: 10.1093/arclin/acn001

Birrer, R. B., and Verumi, S. P. (2004). Depression in later life: a diagnostic and therapeutic challenge. Am. Fam. Physician. 69, 2375-2382.

Botwinick, J., and Storandt, M. (1973). Speed functions, vocabulary ability and age. Percept. Mot. Skills. 36, 1123-1128.

\section{ETHICS STATEMENT}

The studies involving human participants were reviewed and approved by The ethics committee of Besançon university hospital. The patients/participants provided their written informed consent to participate in this study. The RAPID database was validated by an ethics committee: CNIL (French CNIL: 892143). All patients in the memory consultation center receive oral and written information on the possible use of their data for research purposes.

\section{AUTHOR CONTRIBUTIONS}

CM: analysis and interpretation of data, preparation of manuscript, and revising the manuscript. PV, DB, FM, MP, JGa, $\mathrm{EM}, \mathrm{JGi}, \mathrm{JD}, \mathrm{NN}, \mathrm{YB}, \mathrm{MB}$, and $\mathrm{EH}$ : revising the manuscript. GS: acquisition of subjects and data and revising the manuscript. $\mathrm{AM}, \mathrm{ML}, \mathrm{MB}$, and IR: acquisition of subjects and data. GC: study concept and design, acquisition of subjects and data, analysis and interpretation of data, preparation of manuscript, and revising the manuscript. All authors contributed to the article and approved the submitted version.

Bradfield, N., Ellis, K. A., Savage, G., Maruff, P., Burnham, S., Darby, D., et al. (2020). Aggregation of abnormal memory scores and risk of incident Alzheimer's disease dementia: a measure of objective memory impairment in amnestic mild cognitive impairment. J. Int. Neuropsychol. Soc. 27, 146-157. doi: 10.1017/S135561772000079X

Brooks, B. L., Holdnack, J. A., and Iverson, G. L. (2011). Advanced clinical interpretation of the WAIS-IV and the WMS-IV: prevalence of low scores varies by level of intelligence and years of education. Assessment 18, 156-167. doi: $10.1177 / 1073191110385316$

Brooks, B. L., Iverson, G. L., Feldman, H. H., and Holdnack, J. A. (2009a). Minimizing misdiagnosis: psychometric criteria for possible or probable memory impairment. Dement. Geriatr. Cogn. Disord. 27, 439-450. doi: $10.1159 / 000215390$

Brooks, B. L., Iverson, G. L., Koushik, N. S., Mazur-Mosiewicz, A., MacNeill Horton, A. Jr., and Reynolds, C. R. (2013). Prevalence of low scores in children and adolescents on the test of verbal conceptualization and fluency. Appl. Neuropsychol. Child. 2, 70-77. doi: 10.1080/21622965.2012. 742792

Brooks, B. L., Iverson, G. L., Lanting, S. C., Horton, A. M., and Reynolds, C. R. (2012). Improving test interpretation for detecting executive dysfunction in adults and older adults: prevalence of low scores on the test of verbal conceptualization and fluency. Appl. Neuropsychol. Adult. 19, 61-70. doi: 10.1080/09084282.2012.651951

Brooks, B. L., Iverson, G. L., and White, T. (2009b). Advanced interpretation of the Neuropsychological Battery with older adults: base rates analyses, discrepancy scores, and interpreting change. Arch. Clin. Neuropsychol. 24, 647-657. doi: 10.1093/arclin/acp061

Buschke, H., Kuslansky, G., Katz, M., Stewart, W. F., Sliwinski, M. J., Eckholdt, H. M., et al. (1999). Screening for dementia with the memory impairment screen. Neurology. 52, 231-238. doi: 10.1212/wnl.52.2.231

Butters, M. A., Whyte, E. M., Nebes, R. D., Begley, A. E., Dew, M. A., Mulsant, B. H., et al. (2004). The nature and determinants of neuropsychological functioning in late-life depression. Arch. Gen. Psychiatry. 61, 587-595. doi: 10.1001/archpsyc.61.6.587

Butters, M. A., Young, J. B., Lopez, O., Aizenstein, H. J., Mulsant, B. H., Reynolds, C. F., et al. (2008). Pathways linking late-life depression to persistent cognitive impairment and dementia. Dialogues. Clin. Neurosci. 10, 345-357. doi: 10.31887/DCNS.2008.10.3/mabutters 
Cardebat, D., Aithamon, B., and Puel, M. (1995). "Les troubles du langage dans les démences de type Alzheimer," in Neuropsychologie Clinique des Démences: Evvaluations et Prises en Charge, eds F. Eustache and A. Agniel (Marseille: Solal), 213-223.

Chelune, G. J. (2010). Evidence-based research and practice in clinical neuropsychology. Clin. Neuropsychol. 24, 454-467. doi: $10.1080 / 13854040802360574$

Chopard, G., Pitard, A., Ferreira, S., Vanholsbeeck, G., Rumbach, L., and Galmiche, J. (2007). Combining the memory impairment and the Isaacs set test: a practical tool for screening dementias. J. Am. Geriatr. Soc. 55, 1426-1430. doi: 10.1111/j.1532-5415.2007.01271.x

Colette, F., Van der Linden, M., and Salmon, E. (1998). Executive dysfunction in Alzheimer's disease. Cortex 35, 57-72. doi: 10.1016/s0010-9452(08)70785-8

Contador, I., Ferandez-Calvo, B., Cacho, J., Ramos, F., and Lopez-Rolon, A. (2010). Nonverbal memory tasks in early differential diagnosis of Alzheimer's Disease and unipolar depression. Appl. Neuropsychol. 17, 251-261. doi: 10.1080/09084282.2010.525098

Croisile, B., Astier, J. L., Beaumont, C., and Moillion, H. (2011). The 5word test in 37 depressed patients compared with 36 normal controls and 35 patients with mild Alzheimer's disease. Encephale. 37, 127-132. doi: $10.1016 /$ j.encep. 2010.10 .003

Delis, D. C., Kramer, J. H., Kaplan, E., and Ober, B. A. (1987). California Verbal Learning Test: Adult version manual: Research Edn. San Antonio, TX: The Psychological Corporation.

Dierckx, E., Engelborghs, S., Raedt, R., Deyn, P.P., D’Haenens, E., Verte, D., et al. (2011). The ten-word learning task in the differential diagnosis of early Alzheimer's disease and elderly depression: a cross-sectional study. Aging Ment Health. 15, 113-121. doi: 10.1080/13607863.2010.505228

Dierckx, E., Engelborghs, S., Raedt, R., Deyn, P. P., and Ponjaert-kristoffersen, I. (2007). Differentiation between mild cognitive impairment, Alzheimer's disease and depression by means of cued recall. Psychol. Med. 37, 747-755. doi: $10.1017 /$ S003329170600955X

Diniz, B. S., Butters, M. A., Albert, S. M., Dew, M. A., and Reynolds, C. F. (2013). Late-life depression and risk of vascular dementia and Alzheimer's disease: systematic review and meta-analysis of community-based cohort studies. $\mathrm{Br}$. J. Psychiatry 202, 329-335. doi: 10.1192/bjp.bp.112.118307

Dybedal, G. S., Tanum, L., and Bjolseth, T. M. (2013). Neuropsychological functioning in late-life depression. Front. Psychol. 4, 381. doi: $10.3389 /$ fpsyg.2013.00381

Efron, B. (1992). "Bootstrap methods: another Look at the Jackknife," in Breakthroughs in Statistics, Springer Series in Statistics (Perspectives in Statistics), eds S. Kotz, and N.L. Johnson, (New York, NY: Springer) 569-593. doi: 10.1007/978-1-4612-4380-9_41

Elderkin-Thompson, V., Mintz, J., Harron, E., Lavretsky, H., and Kumar, A. (2006). Executive dysfunction and memory in older patients with major and minor depression. Arch. Clin. Neuropsychol. 21, 669-676. doi: 10.1016/j.acn.2006.05.011

Elliot, R. (1998). The neuropsychological profile in unipolar depression. Trends Cogn. Sci. 2, 447-454. doi: 10.1016/s1364-6613(98)01235-2

Fazekas, F., Kleinert, R., Offenbacher, H., Schmidt, R., Kleinert, G., Payer, F., et al. (1993). Pathologic correlates of incidental MRI white matter signal hyperintensities. Neurology 43, 1683-1689.

Federico, D., Thomas-Anterion, C., Borg, C., Foyatier Michel, S., Dirson, S., and Laurent, B. (2008). Usefulness of the 10 pictures reminding test for memory assessment for the diagnosis of Alzheimer's disease, mild cognitive impairment and anxiety/depression. Rev. Med. Intern. 29, 766-772. doi: $10.1016 /$ j.revmed.2008.05.006

Ferreira, S., Vanholsbeeck, G., Chopard, G., Pitard, A., Tio, G., Vandel, P., et al. (2010). Comparative norms of RAPID neuropsychological battery of tests for subjects aged between 50 and 89 years. Rev. Neurol. (Paris). 166, 606-614. doi: 10.1016/j.neurol.2009.12.005

Foldi, N. S., Brickman, A. M., Schaefer, L. A., and Knutelska, M. E. (2003). Distinct serial position and neuropsychological measures differentiate late life depression from normal aging and Alzheimer's Disease. Psychiatry Res. 120, 71-84. doi: 10.1016/s0165-1781(03)00163-x

Folstein, M. F., Folstein, S. E., and McHugh, P. R. (1975). "Mini mental state": a practical method for grading the cognitive state of patients for the clinician. J. Psychiatr. Res. 12, 189-198. doi: 10.1016/0022-3956(75)90026-6
Fossati, P., Coyette, F., Ergis, A., and Allilaire, J. (2002). Influence of age and executive functioning on verbal memory of inpatients with depression. J. Affect. Disord. 68, 261-271. doi: 10.1016/s0165-0327(00) 00362-1

Gasser, A. L., Salamin, V., and Zumbach, S. (2018). Late life depression or prodromal Alzheimer's disease: which tools for the differential diagnosis? Encephale. 44, 52-58. doi: 10.1016/j.encep.2017.03.002

Godefroy, O., Martinaud, O., Verny, C., Mosca, C., Lenoir, H., Bretault, E., et al. (2014). The dysexecutive syndrome of Alzheimer's disease: the GREFEX study. J. Alzheimers Dis. 42, 1203-1208. doi: 10.3233/JAD-140585

Godin, O., Dufouil, C., Ritchie, K., Dartigues, J. F., Tzourio, C., Pérès, K., et al. (2007). Depressive symptoms, major depressive, episode and cognition in the elderly: the three-city study. Neuroepidemiology 28, 101-108. doi: $10.1159 / 000101508$

Gonda, X., Pompili, M., Serafini, G., Carvalho, A. F., Rihmer, Z., and Dome, P. (2004). The role of cognitive dysfunction in the symptoms and remission from depression. Ann. Gen. Psychiatry. 14, 27. doi: 10.1186/s12991-015-0068-9

Grober, E., and Buschke, H. (1987). Genuine memory deficits in dementia. Dev. Neuropsychol. 3, 13-36. doi: 10.1212/wnl.38.6.900

Gualtieri, C. T., and Morgan, D. W. (2008). The frequency of cognitive impairment in patients with anxiety, depression, and bipolar disorder: an unaccounted source of variance in clinical trials. J. Clin. Psychiatry 69, 1122-1130. doi: $10.4088 /$ icp.v69n0712

Gunner, J. H., Miele, A. S., Lynch, J. K., and McCaffrey, R. J. (2012). Performance of non-neurological older adults on the Wisconsin card sorting test and the stroop color-word test: normal variability or cognitive impairment? Arch. Clin. Neuropsychol. 27, 398-405. doi: 10.1093/arclin/acs047

Hammar, A. (2003). Automatic and effortful information processing in unipolar major depression. Scand. J. Psychol. 44, 409-413. doi: 10.1046/j.1467-9450.2003.00361.x

Hammar, A., Lund, A., and Hugdahl, K. (2003). Selective impairment in effortful information processing in major depression. J. Int. Neuropsychol. Soc. 9, 954-959. doi: 10.1017/S1355617703960152

Hasher, L., and Zacks, R. T. (1979). Automatic and effortful processes in memory. J. Exp. Psychol. Gen. 108, 356-388. doi: 10.1037/0096-3445.108.3.356

Haynes, L. E., Barber, D., and Mitchell, I. J. (2004). Chronic antidepressant medication attenuates dexamethasone-induced neuronal death and sublethal neuronal damage in the hippocampus and striatum. Brain Res. 1026, 157-167. doi: $10.1016 /$ j.brainres.2004.05.117

Heaton, R. K. (1991). Comprehensive Norms for an Expanded Halstead-Reitan Battery: A Supplement for the WAIS-R. Odessa: Psychological Assessment, Inc.

Herrmann, L. L., Goodwin, G. M., and Ebmeier, K. P. (2007). The cognitive neuropsychology of depression in the elderly. Psychol. Med. 37, 1693-1702. doi: $10.1017 /$ S0033291707001134

Holdnack, J. A., Tulsky, D. S., Brooks, B. L., Slotkin, J., Gershon, R., Heinemann, A. W., et al. (2017). Interpreting patterns of low scores on the NIH toolbox cognition battery. Arch. Clin. Neuropsychol. 32, 574-584. doi: 10.1093/arclin/acx032

Isaacs, B., and Kennie, A. T. (1973). The set test as an aid to the detection of dementia in old people. Br. J. Psychiatry. 123, 467-470. doi: 10.1192/bjp.123.4.467

Ivaniou, A., Adam, S., Van der Linden, M., Salmon, E., Juillerat, A. C., Mulligan, R., et al. (2005). Memory evaluation with a new cued recall test in patients with mild cognitive impairment and Alzheimer's disease. J. Neurol. 252, 47-55. doi: 10.1007/s00415-005-0597-2

Iverson, G. L., and Brooks, B. L. (2011). "Improving accuracy for identifying cognitive impairment," in The Black Book of Neuropsychology. A SyndromeBased Approach, eds M. R. Schoenberg and J. R. Scott (New York, NY: Springer), 923-950

Iverson, G. L., Brooks, B. L., and Holdnack, J. A. (2008). "Misdiagnosis of cognitive impairment in forensic neuropsychology," in Neuropsychology in the Courtroom Expert Analysis of Reports and Testimony, ed R L. Heilbronner (New York, NY: Guilford Press), 243-266.

Iverson, G. L., Brooks, B. L., Langenecker, S. A., and Young, A. H. (2011). Identifying a cognitive impairment subgroup in adults with mood disorders. J. Affect. Disord. 132, 360-367. doi: 10.1016/j.jad.2011.03.001

Ivins, B. J., Lange, R. T., Cole, W. R., Kane, R., Schwab, K. A., and Iverson, G. L. (2015). Using base rates of low scores to interpret the ANAM4 TBI-MIL 
battery following mild traumatic brain injury. Arch. Clin. Neuropsychol. 30, 26-38. doi: 10.1093/arclin/acu072

Jaeger, J., Berns, S., Uzelac, S., and Davis-Conway, S. (2006). Neurocognitive deficits and disability in major depressive disorder. Psychiatry Res. 145, 39-48. doi: 10.1016/j.psychres.2005.11.011

Kalafat, M., Hugonot-Diener, L., and Poitrenaud, J. (2003). Standardisation et étalonnage français du « Mini Mental State 》(MMS) version GRECO. Rev. Neuropsychol. 13, 209-236.

Karr, J. E., Garcia-Barrera, M. A., Holdnack, J. A., and Iverson, G. L. (2017). Using multivariate base rates to interpret low scores on an abbreviated battery of the Delis-Kaplan Executive Function System. Arch. Clin. Neuropsychol. 32, 297-305. doi: 10.1093/arclin/acw105

Kaup, A. R., Byers, A. L., Falvey, C., Simonsick, E. M., Satterfield, S., Ayonayon, H. N., et al. (2016). Trajectories of depressive symptoms in older adults and risk of dementia. JAMA Psychiatry. 73, 525-531. doi: 10.1001/jamapsychiatry.2016.0004

Kiosses, D. N., Klimstra, S., Murphy, C., and Alexopoulos, G. S. (2001). Executive dysfunction and disability in elderly patients with major depression. Am. J. Geriatr. Psychiatry. 9, 269-274. doi: 10.1097/00019442-200108000-00011

Koening, M. A., Bhalla, R. K., and Butters, M. A. (2014). Cognitive functioning and late-life depression. J. Int. Neuropsychol. Soc. 20, 461-467. doi: $10.1017 /$ S1355617714000198

Korsnes, M. S., and Ulstein, I. D. (2014). Cognitive effects of late life depression: review of neuropsychological findings. J. Behav. Brain. Sci. 4, 141-157. doi: $10.4236 /$ jbbs.2014.43018

Künig, G., Jäger, M., Stief, V., Kaldune, A., Urbaniok, F., and Endrass, J. (2006). The impact of the CERAD-NP on diagnosis of cognitive deficiencies in late onset depression and Alzheimer's disease. Int. J. Geriatr. Psychiatry 21, 911-916. doi: 10.1002/gps.1579

Lamar, M., Charlton, R., Zhang, A., and Kumar, A. (2012). Differential associations between types of verbal memory and prefrontal brain structure in healthy aging and late life depression. Neuropsychologia 50, 1823-1829. doi: 10.1016/j.neuropsychologia.2012.04.007

Lanza, C. E., Sejunaite, K., Steindel, C., Scholz, I., and Riepe, M. W. (2020a). Cognitive profiles in persons with depressive disorder and Alzheimer's disease. Brain Commun. 27, fcaa206. doi: 10.1093/braincomms/fcaa206

Lanza, C. E., Sejunaite, K., Steindel, C., Scholz, I., and Riepe, M. W. (2020b). On the conundrum of cognitive impairment due to depressive disorder in older patients. PloS ONE. 15, e0231111. doi: 10.1371/journal.pone.0231111

Lawton, M., and Brody, E. (1969). Assessment of older people: self-maintaining and instrumental activities of daily living. Gerontologist 9, 179-186. doi: 10.1093/geront/9.3_Part_1.179

Leyhe,T., Reynolds, C. F., Melcher, T., Linnemann, C., Klöppel, S., Blennow, K., et al. (2017). A common challenge in older adults: classification, overlap, and therapy of depression and dementia. Alzheimers. Dement. 13, 59-71. doi: 10.1016/j.jalz.2016.08.007

Lezak, M. D., Howieson, D. B., and Loring, D. W. (2004). Neuropsychological Assessment, 4th Edn. New York, NY: Oxford University Press.

Liguori, C., Pierantozzi, M., Chiaravalloti, A., Sancesario, G. M., Mercuri, N. B., Franchini, F., et al. (2018). When cognitive decline and depression coexist in the elderly: CSF biomarkers analysis can differentiate Alzheimer's Disease from late-life depression. Front. Aging Neurosoci. 10:38. doi: 10.3389/fnagi.2018.00038

Lockwood, K. A., Alexopoulos, G. S., and Van Gorp, W. G. (2002). Executive dysfunction in geriatric depression. Am. J. Psychiatry 159, 1119-1126. doi: 10.1176/appi.ajp.159.7.1119

Ly, M., Karim, H. T., Becker, J. T., Lopez, O. L., Anderson, S. J., Reynolds, C. F., et al. (2021). Late-life depression and increased risk of dementia: a longitudinal cohort study. Transl Psychiatry 11, 147. doi: 10.1038/s41398-02101269-y

Lyketsos, C.G., Lopez, O., Jones, B., Fitzpatrick, A., l., Breitner, J., et al. (2002). Prevalence of neuropsychiatric symptoms in dementia and mild cognitive impairment: results from the Cardiovascular Health Study. JAMA. 288, 1475-1483. doi: 10.1001/jama.288.12.1475

Masse-Sibille, C., Djamila, B., Julie, G., Emmanuel, H., Pierre, V., and Gilles, C. (2018). Predictors of response and remission to antidepressants in geriatric depression: a systematic review. J. Geriatr. Psychiatry Neurol. 31, 283-302. doi: $10.1177 / 0891988718807099$
Mazur-Mosiewicz, A., Trammell, B. A., Noggle, C. A., and Dean, R. S. (2011). Differential diagnosis of depression and Alzheimer's disease using the Cattell-Horn-Carroll theory. Appl. Neuropsychol. 18, 252-262. doi: 10.1080/09084282.2011.595451

McIntyre, R. S., Lophaven, S., and Olsen, C. K. (2014). A randomized, double-blind, placebo-controlled study of vortioxetine on cognitive function in depressed adults. Int. J. Neuropsychopharmacol. 17. 1557-1567. doi: $10.1017 /$ S1461145714000546

McKhann, G., Drachman, D., Folstein, M., Katzman, R., Price, D., and Stadlan, E. M. (1984). Clinical diagnosis of Alzheimer's disease: report of the NINCDSADRDA Work Group under the auspices of department of health and human services task force on Alzheimer's disease. Neurology 34, 939-944. doi: 10.1212/wnl.34.7.939

Merck, C., Charnallet, A., Auriacombe, S., Belliard, S., Hahn-Barma, V., Kremin, H., et al. (2011). La batterie d'évaluation des connaisances sémantiques du GRECO (BECS-GRECO): validation et données normatives. Rev. Neuropsychol. 3, 235-255. doi: 10.3917/rne.034.0235

Metz-Lutz, M. N., Kremin, H., Deloche, G., Hannequin, D., Ferrand, L., Perrier, D., et al. (1991). Standardisation d'un test de dénomination orale: contrôle des effets de l'âge, du sexe et du niveau de scolarité chez les sujets adultes normaux. Rev. Neuropsychol. 1, 73-95.

Meyers, J. E., and Meyers, K. R. (1994). Meyers Scoring System for the Rey Complex Figure Test and the Recognition Trial. Odessa: Psychological Assessment Resources.

Mistridis, P., Egli, S. C., Iverson, G. L., Berres, M., Willmed, K., Welsh-Bohmer, K. A., et al. (2015). Considering the base rates of low performance in cognitively healthy older adults improves the accuracy to identify neurocognitive impairment with the Consortium to Establish a Registry for Alzheimer's Disease-Neuropsychological Assessment Battery (CERAD-NAB). Eur. Arch. Psychiatry Clin. Neurosci. 265, 407-417. doi: 10.1007/s00406-014-0571-z

Nespoulous, J. L., Roch Lecours, A., Lafond, D., Lemay, A., Puel, M., Joanette, Y., et al. (1992). Protocole Montréal-Toulouse D'examen Linguistique de L'aphasie. MT 86. Isbergues: L'Ortho Edition.

O'Hara, R., Coman, E., and Butters, M. A. (2006). "Late life depression," in Clinical Neuropsychology: A Pocket Handbook for Assessment, eds P. G. Snyder, P. D. Nussbaum and D. Robins (Washington, DC: American Psychological Association), 183-209.

Oltra-Cucarella, J., Sánchez-SanSegundo, M., Rubio-Aparicio, M., ArangoLasprilla, J. C., and Ferrer-Cascales, R. (2019). The association between the number of neuropsychological measures and the base rate of low scores. Assessment 28, 955-963. doi: 10.1177/1073191119864646

Osterrieth, P. A. (1944). Le test de copie d'une figure complexe. Arch. Psychol. 30, 206-356

Palmer, B. W., Boone, K. B., Lesser, I. M., and Wohl, M. A. (1998). Base rates of "impaired" neuropsychological test performance among healthy older adults. Arch. Clin. Neuropsychol. 13, 503-511. doi: 10.1016/S0887-6177(97)00037-1

Para, M. A., Abrahams, S., Logie, R. H., and Della Sala, S. (2010). Visual shortterm binding in Alzheimer's disease and depression. J. Neurol. 257, 1160-1169. doi: 10.1007/s00415-010-5484-9

Perry, R. J., Watson, P., and Hodges, J. R. (2000). The nature and staging of attention dysfunction in early (minimal and mild) Alzheimer's disease: relationship to episodic and semantic memory impairment. Neuropsychologia 38, 252-271. doi: 10.1016/s0028-3932(99)00079-2

Pimontel, M. A., Rindskopf, D., Rutherford, B. R., Brown, P. J., Roose, S. P., and Sneed, J. R. (2016). A meta-analysis of executive dysfunction and antidepressant treatment response in late-life depression. Am. J. Geriatr. Psychiatry. 24, 31-41. doi: 10.1016/j.jagp.2015.05.010

Potter, G. G., Kittinger, J. D., Wagner, H. R., Steffens, D. C., and Krishnan, K. R. (2004). Prefrontal neuropsychological predictors of treatment remission in late-life depression. Neuropsychopharmacology 29, 2266-2271. doi: $10.1038 /$ s..npp. 1300551

Potter, G. G., and Steffens, D. C. (2007). Contribution of depression to cognitive impairment and dementia in older adults. Neurologist 13, 105-117. doi: 10.1097/01.nrl.0000252947.15389.a9

Purcel, R. (1997). Neuropsychological function in young patients with unipolar depression. Psychol. Med. 27, 1277-1285. doi: 10.1017/s0033291797005448

Reitan, R. (1958). Validity of the trail-making test as an indicator of organic brain damage. Percept. Motor Skills. 8, 271-276. doi: 10.2466/PMS.8.7.271-276 
Rey, A. (1959). Test de Copie et de Reproduction de Mémoire de Figures Géométriques Complexes. Paris: Éditions Centre de Psychologie Appliquée.

Rivera, D., Olabarrieta-Landa, L., Brooks, B. L., Ertl, M. M., Benito-Sanchez, I., Quijano, M. C., et al. (2019). Multivariate base rates of low scores on tests of learning and memory among latino adult populations. J. Int. Neuropsychol. Soc. 25, 833-844. doi: 10.1017/S135561771900050X

Roca, M., Vives, M., Lopez-Navarro, E., Garcia-Campayo, J., and Gili, M. (2015). Cognitive impairments and depression: a critical review. Actas. Esp. Psiquiatr. $43,187-193$

Rotomskis, A., Margevičiute, R., Germanavičius, A., Kaubrys, G., Budrys, V., and Bagdonas, A. (2015). Differential diagnosis of depression and Alzheimer's disease with the Addenbrooke's Cognitive Examination-Revised (ACE-R). BMC Neurol. 15, 57. doi: 10.1186/s12883-015-0315-3

Royall, D. R., Palmer, R., Chiodo, L. K., and Polk, M. J. (2012). Depressive symptoms predict longitudinal change in executive control but not memory. Int. J. Geriatr. Psychiatry 27, 89-96. doi: 10.1002/gps.2697

Rullier, L., Matharan, F., Barbeau, E. J., Mokri, H., Dartigues, J. F., Pérés, K., et al. (2014). The DMS 48: norms and diagnostic proprieties for Alzheimer's disease in elderly population from the AMI cohort study. Gériatr Psychol Neuropsychiatr Vieil. 12, 321-330. doi: 10.1684/pnv.2014.0486

Rushing, N. C., Sachs-Ericsson, N., and Steffens, D. C. (2014). Neuropsychological indicators of preclinical Alzheimer's disease among depressed older adults. Neuropsychol. Dev. Cogn. B. Aging. Neuropsychol. Cogn. 21, 99-128. doi: $10.1080 / 13825585.2013 .795514$

Scheurich, A., Fellgiebel, A., Schermuly, I., Bauer, S., Wölfges, R., and Müller, M. J. (2008). Experimental evidence for a motivational orgin of cognitive impairment in major depression. Psychol Med. 38, 237-246. doi: $10.1017 /$ S0033291707002206

Schretlen, D. J., Testa, S. M., Winicki, J. M., Pearlson, G. D., and Gordon, B. (2008). Frequency and bases of abnormal performance by healthy adults on neuropsychological testing. J. Int. Neuropsychol. Soc. 14, 436-445. doi: $10.1017 /$ S1355617708080387

Sheline, Y. I., Barch, D. M., Garcia, K., Gersing, K., Pieper, C., Welsh-Bohmer, K., et al. (2006). Cognitive function in late life depression: relationships to depression severity, cerebrovascular risk factors and processing speed. Biol. Psychiatry. 60, 58-65. doi: 10.1016/j.biopsych.2005.09.019

Signoret, J. L., Allard, M., Benoit, N., Bolgert, F., Bonvarlet, M., and Eustache, F. (1998). Evaluation des Troubles de Mémoire et des Désordres Cognitifs Associés. BEC 96. Paris: Ipsen.

Stokholm, J., Vogel, A., and Waldemar, G. (2006). Heterogeneity in executive impairment in patients with very mild Alzheimer's disease. Dement. Geriatr. Cogn. Disord. 22, 54-59. doi: 10.1159/000093262

Story, T. L., Potter, G. G., Attix, D. K., Welsh-Bhomer, K. A., and Steffens, D.C. (2008). Neurocognitive correlates of response to treatment in late-life depression. Am. J. Geriatr. Psychiatry. 16, 752-759. doi: 10.1097/JGP.0b013e31817e739a
Stroop, J. R. (1935). Studies of interference in serial verbal reactions. J. Exp. Psychol. 18, 643-662. doi: 10.1037/h0054651

Swainson, R., Hodges, J. R., Galton, C., Semple, J., Michael, A., Dunn, B., et al. (2001). Early detection and differential diagnosis of Alzheimer's disease and depression with neuropsychological tasks. Dement. Geriatr. Cogn. Disord. 12, 265-280. doi: 10.1159/000051269

Sylvestre, G., Mauny, F., Lavaux, M., Puyraveau, M., Binetruy, M., Vandel, P., et al. (2017). The RAPID neuropsychological test battery for subjects aged 50 to 89 years: from norms to cognitive profile. Eur. Neurol. 78, 247-256. doi: 10.1159/000481090

Thompson, P. J., and Trimble, M. R. (1982). Non-MAOI antidepressants and cognitive functions: a review. Psychol. Med. 12, 539-545. doi: $10.1017 / \mathrm{s} 003329170005563 \mathrm{x}$

Van der Linden, M., Coyette, F., Poitrenaud, J., Kalafat, M., Calicis, F., and Wyns, C. (2004). "L'épreuve de rappel libre/rappel indiçé à 16 items (RL/RI-16)," in L'évaluation des Troubles de la Mémoire. Présentation de Quatre Tests de Mémoire Épisodique (Avec Leur Étalonnage), ed M. Van der Linden (Marseille: Solal), 25-47.

Wechsler, D. (2001). Manuel de l'Echelle Clinique de Mémoire de Wechsler, 3e Édn. Paris: Editions du Centre de Psychologie Appliquée.

Wechsler, D. (2012). Manuel de l'Echelle Clinique de Mémoire de Wechsler, 4e Édn. Paris: Editions du Centre de Psychologie Appliquée.

Zubenko, G. S., Zubenko, W. N., McPherson, S., Spoor, E., Marin, D. B., Farlow, M. R., et al. (2003). A collaborative study of the emergence and clinical features of the major depressive syndrome of Alzheimer's disease. Am. J. Psychiatry 160, 857-866. doi: 10.1176/appi.ajp.160.5.857

Conflict of Interest: The authors declare that the research was conducted in the absence of any commercial or financial relationships that could be construed as a potential conflict of interest.

Publisher's Note: All claims expressed in this article are solely those of the authors and do not necessarily represent those of their affiliated organizations, or those of the publisher, the editors and the reviewers. Any product that may be evaluated in this article, or claim that may be made by its manufacturer, is not guaranteed or endorsed by the publisher.

Copyright (๑) 2021 Masse, Vandel, Sylvestre, Noiret, Bennabi, Mauny, Puyraveau, Barsznica, Dartevelle, Meyer, Binetruy, Lavaux, Ryff, Giustiniani, Magnin, Galmiche, Haffen and Chopard. This is an open-access article distributed under the terms of the Creative Commons Attribution License (CC BY). The use, distribution or reproduction in other forums is permitted, provided the original author $(s)$ and the copyright owner(s) are credited and that the original publication in this journal is cited, in accordance with accepted academic practice. No use, distribution or reproduction is permitted which does not comply with these terms. 